\title{
How relatives of patients with head and neck cancer experience pain, disease progression and treatment: A qualitative interview study
}

Anne Schaller, Gunilla Liedberg and Britt Larsson

\author{
Linköping University Post Print
}

Tweet

N.B.: When citing this work, cite the original article.

Original Publication:

Anne Schaller, Gunilla Liedberg and Britt Larsson, How relatives of patients with head and neck cancer experience pain, disease progression and treatment: A qualitative interview study, 2014, European Journal of Oncology Nursing, (18), 4, 405-410.

http://dx.doi.org/10.1016/j.ejon.2014.03.008

Copyright: Elsevier

http://www.elsevier.com/

Postprint available at: Linköping University Electronic Press

http://urn.kb.se/resolve?urn=urn:nbn:se:liu:diva-109583 


\section{Title page}

How relatives of patients with head and neck cancer experience pain, disease progression and treatment: a qualitative interview study

Corresponding author:

Anne Schaller PhD student, Rehabilitation Medicine, Department of Medical and Health Sciences, Faculty of Health Sciences, Linköping University and Pain and Rehabilitation Centre, County Council of Ostergotland, Linkoping, Sweden.

Email address: anne.schaller@liu.se

Telephone: +46101033970

Gunilla M Liedberg, associated professor, Department of Social and Welfare studies, Faculty of Health Sciences, Linkoping University, Linkoping, Sweden.

Email address: gunilla.liedeberg@liu.se

Britt Larsson, associated professor, Rehabilitation Medicine, Department of Medical and Health Sciences, Faculty of Health Sciences, Linkoping University and Pain and Rehabilitation Centre, County Council of Ostergotland, Linkoping, Sweden.

Email address: britt.larsson@liu.se 


\section{Abstract}

Purpose: This study of relatives to patients with head and neck cancer (HNC) treated with radiotherapy describes how the relatives experienced the patient's situation, especially with respect to pain, and how the relatives themselves experienced the situation.

Methods: Semi-structured interviews of 21 relatives to HNC patients who suffered from pain were conducted, and a qualitative content analysis was performed.

Results: The relatives experienced that the patients suffered from physical, psychological, and social pain. A dark picture consisting of lack of participation and knowledge, psychological distress, and lack of support were reported. Thus, a main category: relatives struggle with loves one's pains related to head and neck cancer treatment and with their own demanding situation - was based on the following four categories: inability to relieve and comprehend the physical suffering of the patients; overwhelming emotions were experienced that affect the patients and the relatives themselves; in need of support from the health care service; and altered daily activities and family roles due to illness and treatment.

Conclusion: In patients physical, psychological, and social pain were prominent and in relatives psychological distress, lack of knowledge and support were experienced. Thus, to reduce pain and anxiety in patients and relatives, the health care should provide relevant knowledge about pain management. The health care should also provide educational interventions that address the psychological and social factors that impact pain for HNC 
patients and their relatives. Well-thought supporting care and easily accessible information about practical concerns should be offered to HNC patients and their relatives.

\section{Keywords}

Head and neck cancer, relatives, pain, qualitative content analysis, interviews

\section{BACKGROUND}

When people suffer from cancer, there is a risk that their family members' quality of life and everyday life will also be negatively affected (Northouse, 2005; Northouse et al., 2012). It has been reported (Juarez and Ferrell, 1996) that relatives may endure a great degree of suffering when their loved one is in pain. The extensive psychosocial impacts on head and neck cancer (HNC) patients are well known (Fischer et al., 2010; Kohda et al., 2005;

Verdonck-de Leeuw et al., 2007). A prospective study of patients with HNC found that living with a spouse lowered the risk of adverse changes in quality of life (Fang et al., 2004). The importance of being surrounded by family, of belonging, and of social support has been shown to contribute to good health and management of cancer diseases including HNC (Patterson et al., 2013; Pinquart and Duberstein, 2010).

Compared to population wide-levels relatives of HNC patients experience higher levels of psychological distress and lower levels of wellbeing (Ross et al., 2010). HNC patients require a considerable amount of care and support and it is difficult for their relatives to take care of them (Precious et al., 2012). To cope with this demanding situation, it may be necessary to 
provide psychological care for both patients and their relatives (Baghi et al., 2007). To date, however, few studies address the life situation of the relatives of HNC patients.

HNC often requires arduous treatment that causes severe adverse effects and sometimes the disease has a poor prognosis - the five-year survival for $\mathrm{HNC}$ is between $23 \%$ and $88 \%$, depending on the type of HNC (Argiris et al., 2008). Painful oral mucositis (OM) is a common adverse effect of radiotherapy treatment (RT), the standard treatment for HNC. About 75\% of patients with HNC experience physical pain despite pain relief treatment (Babin et al., 2008; Epstein et al., 2010).

A recent review (Longacre et al., 2012) did address several important aspects on care givers' to HNC patients situation but did not include care givers' experiences of the HNC patients' pain. This is also an issue which to our knowledge is sparsely studied and important to elucidate.

This qualitative interview study of relatives to patients with HNC treated with RT describes how the relatives perceived the experiences of the patient's situation, especially with respect to pain, and how the relatives themselves experienced the situation. 


\section{METHODS}

\section{Participants}

Relatives of curative HNC patients who had been treated with RT and were referred to the specialized pain care department at the University Hospital, Linköping in southern Sweden, north Europe participated in the study. The department is staffed by anesthesiologists and nurses specialized in pain care and treats inpatients and outpatients. Linköping is located in the county council of Östergötland. Catchment area of the University Hospital of Linköping is about one million people.

To be included, the family member had to be identified by the patient as the closest relative. The patients did not have to specify how they were related to the person they designated as their closest relative (i.e., the patients defined what was meant by closest relative).

Of the 26 relatives asked to participate in the study, 21 agreed to participate. Table 1 shows the demographic make-up (age, sex, relationship, etc.) of the relatives. The data were collected between autumn 2010 and summer 2011 after the relative's patient (i.e., a HNC patient) had completed RT (Table 1). When the interviews were conducted the patients were still current for pain treatment as outpatients at the department. Relatives were provided written and oral information and signed a written consent before the interviews. The regional Ethical Review Board approved the study (2010-05-19).

\section{Interviews and data analysis}


All interviews were conducted by the first author (AS) either in the relative's home $(n=11)$, in the pain care department $(n=9)$, or in a workplace $(n=1)$. The semi-structured qualitative interviews were directed by an interview guide based on Kvale (1996) and Patton (2002). The interview guide, which included predetermined themes to answer the purpose, was developed by the authors to explore the relative's perspective of the patient's pain and of the relative's own situation. The opening question - "Can you describe your experiences during the period your patient underwent the RT treatment?" - gave rich information and often covered or initiated many of the themes. The time of posing the questions related to the predetermined themes varied, depending on how the conversation developed. The interview guide (Table 2) was used as a checklist to guarantee that all themes were discussed. The interviews were audiotaped and transcribed verbatim by an experienced secretary. AS read each transcript and checked them against the tape.

The interviews were analysed with qualitative content analysis as described by Elo and Kyngäs (2008) and Krippendorff (2004). All three authors read the interviews to obtain a sense of the whole with an inductive approach. The interviews were reread systematically, by two of the authors ( $A S, B L$ ), line by line to identify and underline the meaning units of text, relevant for the research aim. Descriptive notes were written in the margins of the transcripts, representing the start of the process called coding. To validate the result the meaning units and codes were compared and discussed by the authors to agreement was reached. A meaning unit consists of a sentence, several sentences, or a paragraph. 
Then all interviews were organized in a computer program for qualitative methodology Nvivo 9 (Edhlund, 2011), and the meaning units were sorted into codes in the program. Further, these codes were sorted into subcategories that were used to develop categories. Based on the categories, a main category was created. This process was conducted by the first author (AS), who frequently consulted the others (BL, $G L)$ regarding excerpts of the primary transcript data and the clustering of the data into subcategories and categories. To increase reliability and trustworthiness several steps were taken to verify the results. These included two analysts performing independent coding processes; a constant review and discussion of emerging subcategories and categories by all three authors; and a systematic checking of the developing categories against supporting quotations. The category system was finally tested by all authors for its consistency within categories and the categories comprising the complete picture (Malterud, 2001). Quotations are used to allow the reader to evaluate the results and were adapted in written language according to Kvale (1996) to avoid incoherent or difficult language. In the Results section, brackets [ ] are used to indicate implied words. 


\section{RESULTS}

A main category (Fig. 1) - relatives struggle with loves one's pains related to head and neck cancer treatment and with their own demanding situation - was based on the following four categories: inability to relieve and comprehend the physical suffering of the patients; overwhelming emotions were experienced that affect the patients and the relatives themselves; in need of support from the health care service; and altered daily activities and family roles due to illness and treatment. Fig. 1 also shows the revealed subcategories. No differences appeared concerning the amount of opinions of spouses versus children in the four categories; they were represented in all categories.

\section{Relatives struggle with loves one's pains related to head and neck cancer treatment and with their own demanding situation}

\section{Inability to relieve and comprehend the physical suffering of the patients}

Most relatives described an extensive physical pain in the patient's mouth and throat region: "The pain he experienced in his mouth was unbearable [according to the patient himself]. I could not fully comprehend it at first; I did not understand it until the first time he opened his mouth and showed me what it looked like" (55-year-old female partner). Fear of medication in patients was described and in some cases medical prescriptions were not followed: ". . . he is terrified of pain. Or, not of pain, but of taking pills" (48-year-old wife). However, some relatives emphasized that the patients tolerated much pain and were capable of handling 
their situation: ". . . he has to take a bit more medicine. ... He was in pain, you see ... he is very resilient and . . . well. ... He has managed it well" (77-year-old wife).

To see their loved ones in severe pain was hard and includes struggles to help relieve the pain of their loved one: ". . . it has been really tough to see him like this. It hurts so much when there is nothing you can do to help; when he has such terrible pain that he has to go and lie down ... it has pained my heart to see him in so much pain" (21-year-old daughter).

Some relatives, however, were unaware and concerned about whether the patient had any pain and thus unable to comprehend the physical suffering of the patients. The relatives' knowledge about good pain relief was sparse and sometimes they were uninformed about which medication patients used. Nevertheless, a few relatives reported an impression of better wellbeing of patients when pain medications were used.

\section{Overwhelming emotions were experienced that affect the patients and the relatives}

\section{themselves}

Many relatives described the patient's difficulties in managing their negative emotions such as fear, anger, and worry. Some relatives regarded the negative emotions in patients as difficult to distinguish from physical pain: "I do not think it is the physical side only, I think it is the psychological side too; he was not in control of his situation, like. He did not get any clear answers. .. . 'Should I [the patient] feel like this? Is it supposed to be this tough?' When you do not know anything about how things ought to be, or will be in the future, the worry makes you sicker than you are" (38-year-old daughter). The relatives described 
overwhelming negative emotions related to the delivering of the diagnosis for patients as well as themselves. The cancer diagnosis was experienced as shocking: "He retreated into himself; he neither slept nor ate, looked, spoke, or did anything. He sat on the couch" (48years-old wife). According to several relatives, the diagnosis was delivered by a group of health professionals in a meeting that included the patients and relatives. It was experienced as an awkward situation with vulnerability and fear about the future and regarded as affecting the psychological mood of both the patients and relatives. One female relative reported her and her husband's experiences: “. . . it was quite tough. ... Even though everyone was frank and accommodating in every way. . . You feel like a little monkey in a cage" (49-year-old wife).

Because of the changed life situation, including emotional crises such as not being able to really help, relatives became worried, especially at night, which negatively affected their sleep: “. . you feel anxious and you think: 'Well then, he is not that old and is he going to die now?' and . . . 'What is happening?' . . 'Will he make it?" (36-year-old daughter). Another reason for the worries of relatives could be the lack of quality sleep of the patients: "He was so anxious during the nights ... Some nights - when he had taken sleeping pills and extra morphine - it did not seem like he breathed that well . . so it really was round-the-clock [care]" (41-year-old wife). Not being able to help a seriously ill patient made some relatives feel lonely and powerless: "I got so mad. . . I l am here by your side, watching you change and seeing how the disease is just eating you up. ... It is tough to stand alongside, looking on" (55-year-old female partner). Several relatives expressed a need to help manage the 
difficult emotions. Psychological help (e.g., talk therapy) both for themselves and for the patients was requested. 


\section{In need of support from the health care service}

The relatives described meetings with several specialized health professionals as lacking an holistic approach i.e. comprehensive view of the patient's situation: ". . there is no one person who really accepts responsibility. Instead, there are a lot of different people involved and he does not feel like any one of them has a complete grasp on his situation" (38-year-old daughter). It was difficult to know whom to contact and suggestions were made by relatives:

"I think, perhaps, that it would be good if there was a nurse charged with overall responsibility, who helped you through all the procedures and made sure that things were done right . . . too much got lost along the way. .." (38-year-old daughter). Relatives wanted more support in terms of extensive information about the disease, treatment side effects, whether the treatment was effective, and a prognosis. There was a lack of straight answers from healthcare providers: "Even if it is not possible to predict the future . . it would be . . a good idea to provide prognoses [along the way]. . " (72-year-old husband).

\section{Altered daily activities and family roles due to illness and treatment}

Fatigue in patients was prominent and related to the illness and regarded by the relatives as to have been increased temporarily in relation to RT. More than half of the patients had to make changes in daily activities because of the illness, fatigue, and weakness, which affected social activities and the roles in the family.

The relatives noted that their patient's pain was mainly associated with eating problems related to $\mathrm{OM}$ as eating was difficult, painful, and time consuming. These meals were often 
described as a major reason for decreased participation in social activities, such as socializing with family and friends. In addition, relatives experienced feelings of guilt related to eating: "... we almost never ate with her; you were, like, ashamed that you were able to eat [when she could not]" (25-year-old daughter). In addition, relatives reported that their appetite decreased: "I did not eat anything either. . . I was not hungry" (78-year-old wife). Almost all the relatives stated the importance of family members and friends supporting the patient during the illness and treatment. Accompanying the patient to medical treatments and to medical appointments are examples of common practical support: "The support everyone gave; like his brother, who helped out like he did and drove us around and was always there for us, and the kids and I too, and, well, everyone around us" (41-year-old wife). Family and friends could also be described as supportive to the relatives especially as a practical support but also as someone to talk to.

The relatives had to encourage the patients to eat and drink, to assist with personal hygiene and dressing wounds, and sometimes to be responsible for medication distribution: "[His] insulin and pills and all that... But it is not just that... have to find a way to juggle our finances... and pay the bills and all that too...so it is a struggle...because everything has to...work out somehow" (84-year-old wife). Dealing with the everyday chores, often previously shared by a couple, and, for some, at the same time managing a job, was perceived as strenuous. Furthermore, to work outside the home also meant that relatives had to leave the patient alone, but employment also meant opportunities for distraction. To cope with the situation during the period of illness, relatives had to show strength: "I feel it 
is been trying many times, this putting on a brave face and making an effort for his sake and the kids' sakes and for my own sake, but . . . eh ... I have taken things one day at a time" (63-year-old wife). Although there had been temporary frictions in some relations, the relationship was still regarded as open, cordial, and close: "a diagnosis like this makes you take a fresh look at your life. ... I have gotten to know mum in a different way. . . Talked about things ... with the result that our relationship has become better and better" (33-yearold daughter). 


\section{Discussion}

The relatives experienced that the patients suffered from substantial physical, psychological, and social pain. This was a challenging situation to support for the relatives. A dark picture consisting of, lack of participation and knowledge, psychological distress, and lack of support from health care providers were reported to affect the relatives themselves.

Insufficient pain relief in patients was extensively reported by the relatives who additionally experienced lack of knowledge of pain relief. Lack of knowledge also has been reported previously as one barrier to adequate pain relief (Aranda et al., 2004; Yates et al., 2004).

A majority of the relatives noted that the patients were capable of handling severe pain. One might speculate that relatives thereby wanted to ensure that the patients deserved the best medical treatment possible. The relatives, however, described sparse knowledge of pain and pain management, a consideration that might have negatively influenced pain treatment. Potential predictors of inadequate pain management include lack of knowledge regarding pain and its management (Meeker et al., 2011; Yates et al., 2004). Previous research has shown that knowledge of pain and participation of patients in pain relief support provides good adherence to pain treatment for cancer patients (Ferrell et al., 1995; Oldham and Kristjanson, 2004). Thus participation of relatives in supporting, for example, regular intake of prescribed medication, short-acting opioids, and transdermal topics, and how to handle adverse effects (Meeker et al., 2011) of these medications would probably have helped the relatives and the patients in their struggles for pain relief. Relatives had a strong desire to 
know about pain and participate in pain management; these desires have also been reported by Yates et al. (2004). However, opportunities for relatives to participate in pain treatment were somewhat limited in our study due to reluctance in some patients and relatives to communicate the extent of their pain.

As previous studies have shown (Aranda et al., 2004; Flemming, 2010), it might be that in our study the relatives and patients hesitated to communicate possible pain to create the impression that the situation was under control and hoping to avoid disease progression. Non-communication about symptoms might also occur since lifestyle factors may contribute to HNC and might be an expression of a need to avoid feelings of guilt. In this study, a great majority of the relatives were women and some of them expressed feelings of guilt, a finding that agrees with a previous study that showed that guilt is common, especially in female patients (Spillers et al., 2008).

In this study and in previous studies (Hodges et al., 2005; Longacre et al., 2012; Ross et al., 2010; Verdonck-de Leeuw et al., 2007; Zwahlen et al., 2008), psychological distresses such as anxiety, fear, and disrupted daily life have been shown to affect the patients and the relatives negatively during the cancer disease progression. Relatives and patients of this study were shocked and disappointed in how the cancer diagnosis was delivered. This might 
partly be related to the seriousness of the diagnosis. Such a reaction stresses the importance of delivering a cancer diagnosis gently and appropriately (Brown et al., 2011; Fujimori and Uchitomi, 2009; Ptacek and Ptacek, 2001) so as to minimize the shock of such a serious diagnosis (Cavers et al., 2012).

When signs of psychological distress manifest, increased support could prevent worsening of the symptoms and even prevent depression (Hodges et al., 2005) for patients and relatives in the post-treatment period. Feelings of loneliness reported by relatives might be related to lack of their ability to help a family member and may also reflect the relatives' fear of the future. Insufficient support for the relatives may be due, at least in part, to feelings of powerlessness and loneliness described by some of them. Low powerlessness, low helplessness, and high trusting relationships in patients in palliative cancer care have been shown to coincide (Milberg and Strang, 2011). Thus a possible way to diminish feelings of powerlessness might be to facilitate and sustain trusting relationships between families and health care providers.

A few relatives experienced a possible interaction between physical and psychological pain in patients. This was the only report of the complexity of pain according to, for example the biopsychosocial model (Gatchel et al., 2007). The model emphasises that neurobiological 
factors interact with psychological factors and the context in the perception of pain. The need of an holistic approach and the need for information about the disease as reported by patients and relatives should be met by health professionals by providing caregiving skills, supportive care, and information, all approaches that have been shown to reduce the burden on patients and increase their ability to support the patient (Chen et al., 2009; Hung et al., 2013).

The relatives in our study stressed the importance of keeping up with daily chores, which certainly are strenuous but also might be a way to find meaning and thereby endure a threatening situation. The supporting role of the relatives, no doubt, included being there for the patient's psychological needs as well as being responsible for practical tasks. This role was challenging and could involve an overwhelming situation that could make it difficult for relatives to organize and maintain their social, emotional, and working lives. When a family member suffers from a life-threatening illness, it is common that the closest patients ignore their own health (Longacre et al., 2012; Ziegert et al., 2006). In our study, health threats in the form of sleeping difficulties and impaired eating habits in relatives were found. The changed role and the worry about the future expressed by the relatives also have been reported in a previous study (Roing et al., 2008). 
The patients and the relatives had only been told about a curative treatment. Nevertheless, they had to handle a situation with pain and nutrition problems, fatigue, and psychological distress i.e., experiences common in a less than optimized palliative situation, by themselves (World Health Organization, 2002). The relatively dark picture of the situation and of the future reported by the relatives in our study differs from at least one other study (Winterling et al., 2008) on curative cancer patients and their patients with expectations for recovery. Treatment and rehabilitation can be preventative, restorative, supportive, and palliative (Fialka-Moser et al., 2003) and should include family members. Cancer patients have rehabilitation needs and their close patients have supporting needs depending on where they are in the continuum of treatment.

Several studies of cancer patients and their relatives have reported that the common experience of a difficult situation has resulted in positive changes in the relationship (Drabe et al., 2013; Ruf et al., 2009). This was also the case in our study in which several relatives noted that they had become closer to the patient.

The methodology of our interview study was well suited for capturing relative's experiences and thoughts in a specific area (Kvale, 1996). An interview guide was used to ensure that important areas were discussed and a standard opening question was used at the beginning of the interview. A non-standard approach in interviews makes it easier to probe and to draw out more substantial answers from the relatives (Kvale, 1996; Patton, 2002). All 
interviews were performed by one of the authors who facilitated a similar approach in the interview situation. The interviewer was an employee of the pain care department but was not involved in these specific patients' and patients' treatment. Moreover, the credibility of the results was validated by each author reading and analysing them separately before comparing and confirming the categories that appeared. The current study, however, has some limitations. There was only one interview per relative. Each category section is rather short. However, we present exhaustive answers, so the short sections are related to the rather short interviews. Some relatives probably had low education level (data not accessible) and were not used to expressing themselves. Furthermore, several relatives were elderly and all relatives found themselves in a challenging situation as a closest relative to a seriously ill person. These factors may have combined to contribute to limited willingness and limited ability to deliver helpful information and strategies.

In conclusion, various dimensions of pain in patients were reflected as a strenuous support situation for the relatives. Experienced lack of participation, support and care from health care also provided psychological distress in relatives. To reduce pain and anxiety in patients and relatives, the health care service should provide relevant knowledge about pain management and psychological support. A possible way to diminish feelings of powerlessness, especially in close relatives, might be to facilitate and sustain trusting relationships between closest relatives and health care providers. To encourage an holistic approach that includes well-thought out care, supporting care, and easily accessible and 
relevant information about practical and medical concerns should be offered to HNC patients and their close relatives.

\section{Conflict of Interest Statement}

None declared.

We have no financial relationship to declare and we have full control of all primary data. 


\section{References}

Aranda, S., Yates, P., Edwards, H., Nash, R., Skerman, H., McCarthy, A., 2004. Barriers to effective cancer pain management: a survey of Australian family caregivers. European journal of cancer care 13, 336-343.

Argiris, A., Karamouzis, M.V., Raben, D., Ferris, R.L., 2008. Head and neck cancer. Lancet 371, 1695-1709.

Babin, E., Sigston, E., Hitier, M., Dehesdin, D., Marie, J.P., Choussy, O., 2008. Quality of life in head and neck cancers patients: predictive factors, functional and psychosocial outcome. European archives of oto-rhino-laryngology 265, 265-270.

Baghi, M., Wagenblast, J., Hambek, M., Radeloff, A., Gstoettner, W., Scherzed, A., Spaenkuch, B., Yuan, J., Hornung, S., Strebhardt, K., Knecht, R., 2007. Demands on caring relatives of head and neck cancer patients. The Laryngoscope 117, 712-716.

Brown, V.A., Parker, P.A., Furber, L., Thomas, A.L., 2011. Patient preferences for the delivery of bad news - the experience of a UK Cancer Centre. European journal of cancer care 20, 56-61.

Cavers, D., Hacking, B., Erridge, S.E., Kendall, M., Morris, P.G., Murray, S.A., 2012. Social, psychological and existential well-being in patients with glioma and their caregivers: a qualitative study. Canadian Medical Association journal 184, E373-382.

Chen, S.C., Tsai, M.C., Liu, C.L., Yu, W.P., Liao, C.T., Chang, J.T., 2009. Support needs of patients with oral cancer and burden to their family caregivers. Cancer nursing 32 , 473-481.

Drabe, N., Wittmann, L., Zwahlen, D., Buchi, S., Jenewein, J., 2013. Changes in close relationships between cancer patients and their partners. Psycho-oncology 22, 13441352.

Edhlund, B.M., 2011. Nvivo 9 essentials : your guide to the world's most powerful qualitative data analysis software. Form \& Kunskap AB, Stallarholmen, Sweden.

Elo, S., Kyngas, H., 2008. The qualitative content analysis process. Journal of advanced nursing 62, 107-115.

Epstein, J.B., Hong, C., Logan, R.M., Barasch, A., Gordon, S.M., Oberle-Edwards, L., McGuire, D., Napenas, J.J., Elting, L.S., Spijkervet, F.K., Brennan, M.T., 2010. A systematic review of orofacial pain in patients receiving cancer therapy. Supportive care in cancer 18, 1023-1031.

Fang, F.M., Chien, C.Y., Kuo, S.C., Chiu, H.C., Wang, C.J., 2004. Changes in quality of life of head-and-neck cancer patients following postoperative radiotherapy. Acta oncologica 43, 571-578.

Ferrell, B.R., Grant, M., Chan, J., Ahn, C., Ferrell, B.A., 1995. The impact of cancer pain education on family caregivers of elderly patients. Oncology Nursing Forum 22, 12111218.

Fialka-Moser, V., Crevenna, R., Korpan, M., Quittan, M., 2003. Cancer rehabilitation: particularly with aspects on physical impairments. Journal of rehabilitation medicine 35, 153-162. 
Fischer, D.J., Villines, D., Kim, Y.O., Epstein, J.B., Wilkie, D.J., 2010. Anxiety, depression, and pain: differences by primary cancer. Supportive care in cancer $18,801-810$.

Flemming, K., 2010. The use of morphine to treat cancer-related pain: a synthesis of quantitative and qualitative research. Journal of pain and symptom management 39, 139-154.

Fujimori, M., Uchitomi, Y., 2009. Preferences of cancer patients regarding communication of bad news: a systematic literature review. Japanese journal of clinical oncology 39 , 201-216.

Gatchel, R.J., Peng, Y.B., Peters, M.L., Fuchs, P.N., Turk, D.C., 2007. The biopsychosocial approach to chronic pain: scientific advances and future directions. Psychological bulletin 133, 581-624.

Hodges, L.J., Humphris, G.M., Macfarlane, G., 2005. A meta-analytic investigation of the relationship between the psychological distress of cancer patients and their carers. Social science \& medicine 60, 1-12.

Hung, H.C., Tsai, M.C., Chen, S.C., Liao, C.T., Chen, Y.R., Liu, J.F., 2013. Change and predictors of social support in caregivers of newly diagnosed oral cavity cancer patients during the first 3 months after discharge. Cancer nursing 36, E17-24.

Juarez, G., Ferrell, B.R., 1996. Family and caregiver involvement in pain management. Clinics in geriatric medicine 12, 531-547.

Kohda, R., Otsubo, T., Kuwakado, Y., Tanaka, K., Kitahara, T., Yoshimura, K., Mimura, M., 2005. Prospective studies on mental status and quality of life in patients with head and neck cancer treated by radiation. Psycho-oncology 14, 331-336.

Krippendorff, K., 2004. Content analysis : an introduction to its methodology. Sage, Thousand Oaks, Calif.

Kvale, S., 1996. Interviews : an introduction to qualitative research interviewing. Sage Publications, Thousand Oaks, Calif.

Longacre, M.L., Ridge, J.A., Burtness, B.A., Galloway, T.J., Fang, C.Y., 2012. Psychological functioning of caregivers for head and neck cancer patients. Oral oncology 48, 18-25.

Malterud, K., 2001. The art and science of clinical knowledge: evidence beyond measures and numbers. Lancet 358, 397-400.

Meeker, M.A., Finnell, D., Othman, A.K., 2011. Family caregivers and cancer pain management: a review. Journal of family nursing 17, 29-60.

Milberg, A., Strang, P., 2011. Protection against perceptions of powerlessness and helplessness during palliative care: the family members' perspective. Palliative \& Supportive Care 9, 251-262.

Northouse, L., 2005. Helping families of patients with cancer. Oncology Nursing Forum 32, 743-750.

Northouse, L., Williams, A.L., Given, B., McCorkle, R., 2012. Psychosocial care for family caregivers of patients with cancer. Journal of Clinical Oncology 30, 1227-1234.

Oldham, L., Kristjanson, L.J., 2004. Development of a pain management programme for family carers of advanced cancer patients. International journal of palliative nursing 10, 91-99. 
Patterson, J.M., Rapley, T., Carding, P.N., Wilson, J.A., McColl, E., 2013. Head and neck cancer and dysphagia; caring for carers. Psycho-oncology 22, 1815-1820.

Patton, M.Q., 2002. Qualitative research and evaluation methods. Sage Publications, Thousand Oaks, Calif.

Pinquart, M., Duberstein, P.R., 2010. Associations of social networks with cancer mortality: a meta-analysis. Critical reviews in oncology/hematology 75, 122-137.

Precious, E., Haran, S., Lowe, D., Rogers, S.N., 2012. Head and neck cancer patients' perspective of carer burden. The British journal of oral \& maxillofacial surgery 50 , 202-207.

Ptacek, J.T., Ptacek, J.J., 2001. Patients' perceptions of receiving bad news about cancer. Journal of Clinical Oncology 19, 4160-4164.

Roing, M., Hirsch, J.M., Holmstrom, I., 2008. Living in a state of suspension--a phenomenological approach to the spouse's experience of oral cancer. Scandinavian journal of caring sciences 22, 40-47.

Ross, S., Mosher, C.E., Ronis-Tobin, V., Hermele, S., Ostroff, J.S., 2010. Psychosocial adjustment of family caregivers of head and neck cancer survivors. Supportive care in cancer 18, 171-178.

Ruf, M., Buchi, S., Moergeli, H., Zwahlen, R.A., Jenewein, J., 2009. Positive personal changes in the aftermath of head and neck cancer diagnosis: a qualitative study in patients and their spouses. Head \& neck 31, 513-520.

Spillers, R.L., Wellisch, D.K., Kim, Y., Matthews, B.A., Baker, F., 2008. Family caregivers and guilt in the context of cancer care. Psychosomatics 49, 511-519.

Verdonck-de Leeuw, I.M., Eerenstein, S.E., Van der Linden, M.H., Kuik, D.J., de Bree, R., Leemans, C.R., 2007. Distress in spouses and patients after treatment for head and neck cancer. The Laryngoscope 117, 238-241.

Winterling, J., Glimelius, B., Nordin, K., 2008. The importance of expectations on the recovery period after cancer treatment. Psycho-oncology 17, 190-198.

World Health Organization, W., 2002. National cancer control programmes : policies and managerial guidelines. . World Health Organization, Geneva.

Yates, P., Aranda, S., Edwards, H., Nash, R., Skerman, H., McCarthy, A., 2004. Family caregivers' experiences and involvement with cancer pain management. Journal of Palliative Care 20, 287-296.

Ziegert, K., Fridlund, B., Lidell, E., 2006. Health in everyday life among spouses of haemodialysis patients: a content analysis. Scandinavian journal of caring sciences 20, 223-228.

Zwahlen, R.A., Dannemann, C., Gratz, K.W., Studer, G., Zwahlen, D., Moergeli, H., Drabe, N., Buchi, S., Jenewein, J., 2008. Quality of life and psychiatric morbidity in patients successfully treated for oral cavity squamous cell cancer and their wives. Journal of oral and maxillofacial surgery 66, 1125-1132. 
Figure 1.

\section{Relatives struggle with loves one's pains related to head and neck cancer treatment and with their own demanding situation}

\begin{tabular}{|c|c|c|c|}
\hline $\begin{array}{l}\text { Inability to relieve } \\
\text { and comprehend the } \\
\text { physical suffering of } \\
\text { the patients }\end{array}$ & $\begin{array}{l}\text { Overwhelming } \\
\text { emotions were } \\
\text { experienced that } \\
\text { affect the patients } \\
\text { and the relatives } \\
\text { themselves }\end{array}$ & $\begin{array}{l}\text { In need of support } \\
\text { from the health care } \\
\text { service }\end{array}$ & $\begin{array}{l}\text { Altered daily } \\
\text { activities and family } \\
\text { roles due to the } \\
\text { illness and } \\
\text { treatment }\end{array}$ \\
\hline $\begin{array}{l}{ }^{1} \text { Extensive physical } \\
\text { pain } \\
{ }^{1} \text { Fear of medication } \\
{ }^{1} \text { Tolerated much pain } \\
{ }^{2} \text { Struggles to relieve } \\
\text { the pain } \\
{ }^{2} \text { Inadequate } \\
\text { knowledge about pain } \\
\text { and pain relief }\end{array}$ & $\begin{array}{l}{ }^{1} \text { Negative emotions } \\
\text { with feeling of fear, } \\
\text { anger and unfairness } \\
{ }^{1} \text { Psychological } \\
\text { symptoms were } \\
\text { difficult to distinguish } \\
\text { from physical pain } \\
{ }^{3} \text { Great uncertainty of } \\
\text { the cancer diagnosis } \\
{ }^{3} \text { Affecting the } \\
\text { psychological mood } \\
{ }^{2} \text { A state of worries } \\
{ }^{2} \text { Loneliness and } \\
\text { powerlessness }\end{array}$ & $\begin{array}{l}{ }^{2} \text { The holistic approach } \\
\text { was missing } \\
{ }^{2} \text { Challenges about } \\
\text { information } \\
{ }^{2} \text { Lack of information }\end{array}$ & $\begin{array}{l}{ }^{1} \text { Decreased } \\
\text { participation in social } \\
\text { activities } \\
{ }^{2} \mathrm{~A} \text { feeling of } \\
\text { embarrassment } \\
{ }^{2} \text { Emotional and } \\
\text { practical support for } \\
\text { the patient } \\
{ }^{2} \mathrm{~A} \text { strenuous situation } \\
{ }^{2} \mathrm{We} \text { came closer to } \\
\text { each other }\end{array}$ \\
\hline
\end{tabular}


Table 1.

Characteristics of the 21 relatives and

their patients (HNC patients)

\begin{tabular}{|c|c|}
\hline & Numbe \\
\hline \multicolumn{2}{|l|}{ Sex } \\
\hline Female & 18 \\
\hline Male & 3 \\
\hline \multicolumn{2}{|l|}{ Age } \\
\hline 20-39 years & 6 \\
\hline $40-59$ years & 6 \\
\hline $60-89$ years & 9 \\
\hline \multicolumn{2}{|c|}{ Relationship to the HNC patient } \\
\hline Spouse & 12 \\
\hline Cohabitant & 3 \\
\hline Child & 6 \\
\hline \multicolumn{2}{|c|}{ Tumour site (patient) } \\
\hline Oral cavity & 8 \\
\hline Pharynx & 6 \\
\hline Larynx & 4 \\
\hline Others & 3 \\
\hline \multicolumn{2}{|c|}{$\begin{array}{l}\text { Classification of malignant } \\
\text { tumours according to TNM }{ }^{1} \\
\text { (patient) }\end{array}$} \\
\hline I & 3 \\
\hline II & 3 \\
\hline III & 5 \\
\hline III & 10 \\
\hline \multicolumn{2}{|c|}{$\begin{array}{l}\text { Time point }{ }^{2} \text { of interview of } \\
\text { relatives }\end{array}$} \\
\hline$<2$ months & 9 \\
\hline 2-4 months & 8 \\
\hline$>4$ months & 4 \\
\hline
\end{tabular}


Table 2.

Interview guide

Can you describe your experiences during the period your relative (HNC patient) underwent the RT treatment?

- Pain

- Symptoms

o Health

- Wellness

○ Family

How is the relationship between you and your closest relative (HNC patient)?

Can you describe if the relationship has been affected since the treatment or diagnosis?

- In what ways

o Your role

What do you feel have helped your relative (HNC patient) during the treatment?

- What has been the most important?

- What has been less good?

- What support do you need as a relative? 